\title{
Miscibility in Blends of Stereoregular Poly(methyl methacrylate)s with Chlorinated Polyethylenes and Chlorinated Poly(vinyl chloride)s
}

\author{
Hiroyoshi UEDA ${ }^{\dagger}$ and Frank E. KaRASZ \\ Department of Polymer Science and Engineering, University of Massachusetts, \\ Amherst, Massachusetts 01003, U.S.A.
}

(Received June 28, 1993)

\begin{abstract}
Critical miscibility phenomena in binary blends of atactic, isotactic, or syndiotactic poly(methyl methacrylate)s (a-, i-, and s-PMMA) with chlorinated polyethylene (CPE) or chlorinated poly(vinyl chloride) (CPVC), each with systematically varying degrees of chlorination, were studied by measuring the glass transitions by differential scanning calorimetry. These systems show lower critical solution temperatures (LCSTs). The reversibilities of phase separation above the LCST and homogenization below the LCST in the systems were confirmed. The respective miscibility diagrams, i.e., miscibility as a function of temperature and composition expressed in chlorine weight percent, typically display "miscibility windows." Both CPE and CPVC are more miscible with s- and a-PMMA than with i-PMMA. The miscibility behavior of the PMMA/CPE system differs from that of the PMMA/CPVC system reflecting the influence of the microstructures of CPE and CPVC.
\end{abstract}

KEY WORDS Chlorinated Polyethylene / Miscibility / Glass Transition / Upper Critical Solution Temperature / Lower Critical Solution Temperature / Microstructure /

Critical miscibility phenomena in blends of copolymers have been extensively studied. ${ }^{1-15}$ Quantitatively, miscibility may be defined in terms of a net interaction parameter of the mixture, which in turn can be expressed as functions of the copolymer compositions and parameters representing interactions between segments in the copolymers. The segmental interaction parameters are determined by the chemical structures and, as a second order effect, the microstructures of the component polymers. Thus it has been found that the segmental interaction parameters for blends of chlorinated polyethylenes (CPEs) are indeed influenced by adjacent segments. ${ }^{10,11,14}$ The effect of adjacent segments on the interaction parameter can be formally represented by terms involving interactions between sets of triads; thus miscibility depends on the comonomer sequence distribution.

Stereoregularity (also a sequence distribution effect) and branching may also influence the miscibility of polymer blends. In fact, miscibility in poly(methyl methacrylate) (PMMA)/poly(vinyl chloride) (PVC) blends has been found, not surprisingly, to be influenced by the tacticity of PMMA ${ }^{16-19}$ : PVC is more miscible with syndiotactic PMMA (s-PMMA) than with isotactic PMMA (iPMMA). A similar effect of tacticity on miscibility has been reported for the blend of poly(vinylidene fluoride) (PVDF) and poly(ethyl methacrylate) (PEMA) ${ }^{20}$ : PVDF is more miscible with syndiotactic PEMA and atactic PEMA than with isotactic PEMA. Alternative explanations for the influence of

† Present address: Dainippon Ink and Chemicals, Inc., Kanto R\&D Center, 12 Yawata-Kaigandori, Ichihara-shi, Chiba 290, Japan. 
tacticity on miscibility have been proposed. Schurer et al., ${ }^{16}$ for example, suggested that the influence of tacticity could be attributed to different chain conformations of polymers of the different tacticities. Similarly Vorenkamp et al. ${ }^{18}$ attributed the difference in miscibility behavior between s- or a-PMMA/PVC and i-PMMA/ PVC blends to the difference in flexibilities of the various polymer chains. However, a thorough understanding of the effects of tacticity on miscibility phenomena has not yet been achieved.

Miscibility in mixtures of PMMA with $\mathrm{CPE}^{21,22}$ and chlorinated poly(vinyl chloride) $(\mathrm{CPVC})^{23,24}$ has also been studied. Tremblay and Prud'homme ${ }^{23}$ examined the miscibility of blends of alkyl polymethacrylates with chlorinated polymers (including PVC, CPE, and CPVC) and found that a high chlorine content of the chlorinated polymer $(48-56 \mathrm{wt} \% \mathrm{Cl})$ and an optimum $\mathrm{CH}_{2} / \mathrm{COO}$ ratio in the polymethacrylate were required to obtain miscibility. However, CPE, PVC, and CPVC all have different sequence distributions of $\mathrm{CH}_{2}$ and $\mathrm{CHCl}$; thus these polymers can be expected to display different miscibility behaviors when blended with PMMA. In this contribution we discuss the combined effects of the tacticity of PMMA and microstructure of the chlorinated hydrocarbons on the critical miscibility phenomena in mixtures of PMMA with CPEs and CPVCs with different chlorine contents. We demonstrate that the effects can be quantitatively accounted for in terms of copolymercopolymer miscibility theory. ${ }^{10,11}$

\section{EXPERIMENTAL}

Chlorinated polyethylenes (CPEs) were prepared by solution photochlorination of a master batch of a linear high-density polyethylene (Pressure Chemical Co., $M_{w}=23700$, $M_{n}=9420$ ) following the procedures of Saito et al. ${ }^{25}$ In this procedure the polyethylene was dissolved in 1,1,2,2-tetrachloroethane $(1 \% \mathrm{w} / \mathrm{v}$ solution) at $110^{\circ} \mathrm{C}$. Chlorine was bubbled through the solution and the photoreaction was initiated with a tungsten lamp. CPEs with different chlorine contents were obtained by removing aliquots of this solution at appropriate times of reaction. The samples were precipitated with a tenfold excess of methanol and dried at $60^{\circ} \mathrm{C}$ for 1 week.

Solution chlorinated poly(vinyl chloride) (CPVC) and the base poly(vinyl chloride) (PVC) $\left(M_{w}=209000, M_{n}=136000\right)$ were supplied by B. F. Goodrich Co. The chlorine content of the various CPEs, expressed in terms of weight percentage, were determined by elemental analysis; the chlorine content of the various CPVCs were supplied by B. F. Goodrich Co. Isotactic and syndiotactic poly(methyl methacrylate)s (i-PMMA, s-PMMA) were obtained from Polymer Laboratories, Ltd., Church Stretton, U. K. (i-PMMA: $M_{w}=132000, M_{n}=26000$; s-PMMA: 319000 , $\left.M_{n}=155000\right){ }^{26}$ Atactic PMMA (a-PMMA) was obtained from Polysciences, Inc. $\left(M_{w}=\right.$ $81800, M_{n}=46700$ ).

In preparing a blend, PMMA and either CPE or CPVC of a selected chlorine content were dissolved in tetrahydrofuran $(1 \% \mathrm{w} / \mathrm{v})$; the composition of the blends studied here was $50 / 50 \mathrm{wt} \%$. The mixtures were coprecipitated with a tenfold excess of methanol. The precipitated powders were dried at 50 to $60^{\circ} \mathrm{C}$ for 7 days under reduced pressure in a vacuum oven.

The miscibility of the blends was determined by observing the glass transition temperatures by differential scanning calorimetry (PerkinElmer DSC-4). The $T_{\mathrm{g}}$ 's were conveniently determined from the maxima in plots of $\mathrm{d} C_{\mathrm{p}} / \mathrm{d} T$ versus temperature. Selected thermal histories were imposed by annealing the samples in the DSC. Samples were heated at $200^{\circ} \mathrm{C} \mathrm{min}^{-1}$ to the desired temperature and annealed for 15 min unless otherwise noted. The samples were then quenched to a temperature below that of the lower component $T_{\mathrm{g}}$. Thermal analyses of the annealed samples were carried out at a heating rate of $20^{\circ} \mathrm{C} \mathrm{min}^{-1}$. 


\section{RESULTS AND DISCUSSION}

As discussed in a previous contribution, ${ }^{27}$ chlorinated polyethylenes and chlorinated poly(vinyl chloride)s may be considered as copolymers consisting of $\mathrm{CH}_{2}, \mathrm{CHCl}$, and $\mathrm{CCl}_{2}$ units. The content of $\mathrm{CCl}_{2}$ units can be neglected, except at the highest chlorine contents, therefore CPE and CPVC can be considered random copolymers expressed as $\left(\mathrm{A}_{x} \mathrm{~B}_{1-x}\right)_{n}$, where $\mathrm{A} \equiv \mathrm{CH}_{2}$ and $\mathrm{B} \equiv \mathrm{CHCl}$ for $\mathrm{CPEs}$, and $\mathrm{A}^{\prime} \equiv \mathrm{CH}_{2} \mathrm{CHCl}$ and $\mathrm{B}^{\prime} \equiv \mathrm{CHCl}-$ $\mathrm{CHCl}$ for CPVCs. Isotactic and syndiotactic poly(methyl methacrylate) are homopolymers, but their repeat units may be expressed differently: i-PMMA and s-PMMA may be defined as $(\mathrm{C})_{n} \equiv(\mathrm{ADAD})_{n}$ and $\left(\mathrm{C}^{\prime}\right)_{n} \equiv$ $\left(\mathrm{ADAD}^{\prime}\right)_{n}$, respectively, where $\mathrm{A} \equiv \mathrm{CH}_{2}, \mathrm{D} \equiv$ $\mathrm{CH}_{3}-\stackrel{\text { I }}{\mathrm{I}}-\mathrm{COOCH}_{3}$, and $\mathrm{D}^{\prime} \equiv \mathrm{CH}_{3} \mathrm{OOC}-\stackrel{\mathrm{C}}{\mathrm{C}}-$ $\mathrm{CH}_{3}$. Thus these PMMA's may also be regarded as copolymers for the purposes of the following analysis. Totally atactic poly(methyl methacrylate) can be expressed as a random copolymer $\left(\mathrm{C}_{0.5} \mathrm{C}_{0.5}^{\prime}\right)_{n}$.

The miscibility behavior in i-, a-, or sPMMA/CPE or CPVC blends may be analyzed by using a first-order mean-field treatment for binary mixtures of random copolymers. ${ }^{6-8}$ According to the treatment by ten Brinke $e t$ al., ${ }^{7}$ the overall interaction parameters of $\mathrm{i}-, \mathrm{s}-$, and a-PMMA with CPE or CPVC can be written as

$$
\begin{gathered}
\chi_{\mathrm{blend}}^{\mathrm{i}} \equiv \chi_{\mathrm{AB}} x^{2}+\left(\chi_{\mathrm{AC}}-\chi_{\mathrm{BC}}-\chi_{\mathrm{AB}}\right) x+\chi_{\mathrm{BC}} \\
\chi_{\text {blend }}^{\mathrm{s}} \equiv \chi_{\mathrm{AB}} x^{2}+\left(\chi_{\mathrm{AC}^{\prime}}-\chi_{\mathrm{BC}^{\prime}}-\chi_{\mathrm{AB}}\right) x+\chi_{\mathrm{BC}^{\prime}} \\
\chi_{\text {blend }}^{\mathrm{a}} \equiv \chi_{\mathrm{AB}} x^{2}+\left\{\frac{1}{2}\left(\chi_{\mathrm{AC}}+\chi_{\mathrm{AC}^{\prime}}\right)\right. \\
\left.-\frac{1}{2}\left(\chi_{\mathrm{BC}}+\chi_{\mathrm{BC}^{\prime}}\right)-\chi_{\mathrm{AB}}\right\} x \\
+\frac{1}{2}\left(\chi_{\mathrm{BC}}+\chi_{\mathrm{BC}^{\prime}}\right)-\frac{1}{4} \chi_{\mathrm{CC}^{\prime}}
\end{gathered}
$$

where

$$
\begin{aligned}
& \chi_{\mathrm{AC}} \equiv \chi_{\mathrm{A} / \mathrm{ADAD}}, \quad \chi_{\mathrm{AC}^{\prime}} \equiv \chi_{\mathrm{A} / \mathrm{ADAD}^{\prime}} \\
& \chi_{\mathrm{BC}} \equiv \chi_{\mathbf{B} / \mathrm{ADAD}}, \quad \chi_{\mathrm{BC}^{\prime}} \equiv \chi_{\mathbf{B} / \mathrm{ADAD}^{\prime}}, \\
& \chi_{\mathrm{CC}^{\prime}}=\chi_{\mathrm{ADAD} / \mathrm{ADAD}^{\prime}}
\end{aligned}
$$

and, for CPVC, the respective $\chi$ 's with $\mathrm{A}^{\prime}$ and $B^{\prime}$ subscripts are employed. The miscibilityimmiscibility boundary is determined by

$$
\chi_{\text {blend }}-\chi_{0}=0
$$

where $\chi_{0}$ is the entropy related constant

$$
\chi_{0}=\frac{1}{2}\left(n_{1}^{-1 / 2}+n_{2}^{-1 / 2}\right)^{2}
$$

where $n_{\mathrm{i}}$ is the degree of polymerization of the $i$ th component. When $\chi_{\text {blend }}-\chi_{0}<0$, the mixture is miscible. Thus the miscibility boundaries for i-, s-, and a-PMMA with CPE or with CPVC are determined by

$$
\begin{aligned}
\chi_{\mathrm{AB}} x^{2} & +\left(\chi_{\mathrm{AC}}-\chi_{\mathrm{BC}}-\chi_{\mathrm{AB}}\right) x+\chi_{\mathrm{BC}}-\chi_{0}^{\mathrm{i}}=0 \\
\chi_{\mathrm{AB}} x^{2}+ & \left(\chi_{\mathrm{AC}^{\prime}}-\chi_{\mathrm{BC}^{\prime}}-\chi_{\mathrm{AB}}\right) x+\chi_{\mathrm{BC}^{\prime}}-\chi_{0}^{\mathrm{s}}=0 \\
\chi_{\mathrm{AB}} x^{2}+ & \left\{\frac{1}{2}\left(\chi_{\mathrm{AC}}+\chi_{\mathrm{AC}^{\prime}}\right)\right. \\
& \left.-\frac{1}{2}\left(\chi_{\mathrm{BC}}+\chi_{\mathrm{BC}^{\prime}}\right)-\chi_{\mathrm{AB}}\right\} x \\
+ & \frac{1}{2}\left(\chi_{\mathrm{BC}}+\chi_{\mathrm{BC}^{\prime}}\right)-\frac{1}{4} \chi_{\mathrm{CC}^{\prime}}-\chi_{0}^{\mathrm{a}}=0
\end{aligned}
$$

Equations 7-9 are quadratic functions of polymer compositions in terms of $\mathrm{CH}_{2}$ (for $\mathrm{CPE}$ ) or $\mathrm{CH}_{2} \mathrm{CHCl}$ (for $\mathrm{CPVC}$ ) content. The miscibility boundaries of these systems define a region of miscibility, the "miscibility window," which can be shown graphically in several forms. $^{7}$

When a system displays a miscibility window in the temperature-copolymer composition plane, the copolymer composition $x_{\mathrm{m}}\left(T_{\mathrm{m}}\right)$ at the maximum of miscibility $T_{\mathrm{m}}$ for an i-, s-, or a-PMMA system $\left(x_{\mathrm{m}}^{\mathrm{i}}, x_{\mathrm{m}}^{\mathrm{s}}, x_{\mathrm{m}}^{\mathrm{a}}\right)$ is expressed as ${ }^{7}$

$$
x_{\mathrm{m}}^{\mathrm{i}}\left(T_{\mathrm{m}}\right)=\frac{1}{2}+\frac{\chi_{\mathrm{BC}}-\chi_{\mathrm{AC}}}{2 \chi_{\mathrm{AB}}}
$$




$$
\begin{gathered}
x_{\mathrm{m}}^{\mathrm{s}}\left(T_{\mathrm{m}}\right)=\frac{1}{2}+\frac{\chi_{\mathrm{BC}^{\prime}}-\chi_{\mathrm{AC}^{\prime}}}{2 \chi_{\mathrm{AB}}} \\
x_{\mathrm{m}}^{\mathrm{a}}\left(T_{\mathrm{m}}\right)=\frac{1}{2}+\frac{1}{4}\left(\frac{\chi_{\mathrm{BC}}-\chi_{\mathrm{AC}}+\chi_{\mathrm{BC}^{\prime}}-\chi_{\mathrm{AC}^{\prime}}}{\chi_{\mathrm{AB}}}\right)
\end{gathered}
$$

If the temperature at $x_{\mathrm{m}}\left(T_{\mathrm{m}}\right)$ for the three systems is the same, then, from eq $4, x_{\mathrm{m}}^{\mathrm{a}}$ is an average of $x_{\mathrm{m}}^{\mathrm{i}}$ and $x_{\mathrm{m}}^{\mathrm{s}}$ :

$$
x_{\mathrm{m}}^{\mathrm{a}}=\frac{1}{2}\left(x_{\mathrm{m}}^{\mathrm{i}}+x_{\mathrm{m}}^{\mathrm{s}}\right)
$$

The boundaries of the miscibility window also define critical solution temperatures which, depending on the nature of the system, may be of the lower (LCST) or upper (UCST) type. LCSTs of PMMA/CPE blends have been reported. ${ }^{21,22}$ Figures 1, 2, and 3 indeed show examples of derivative DSC thermograms of, respectively, a-, i-, and s-PMMA/CPE mixtures showing LCSTs. Thus the samples annealed

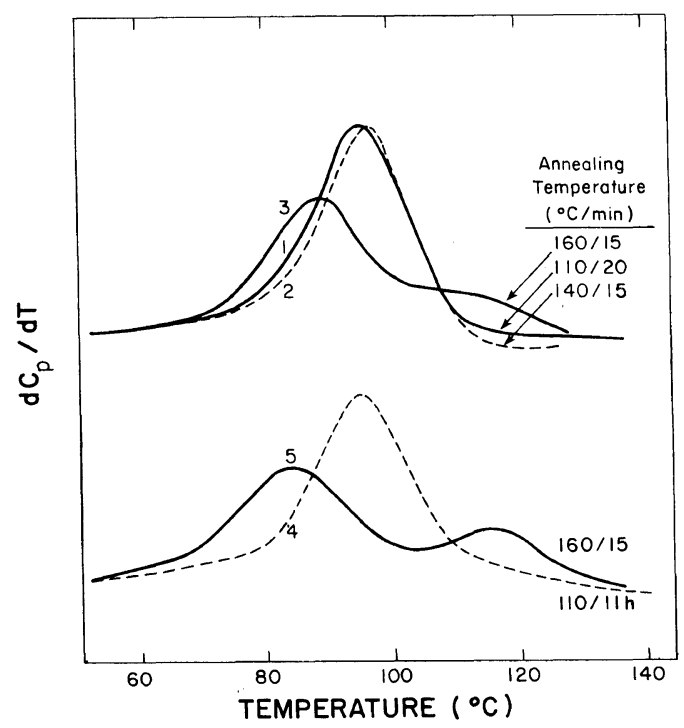

Figure 1. Derivative DSC thermograms $\left(\mathrm{d} C_{\mathrm{p}} / \mathrm{d} T\right.$ vs. $\left.T\right)$ of $50 / 50 \mathrm{wt} \%$ blends of atactic poly(methyl methacrylate) and chlorinated polyethylene containing $58.5 \mathrm{wt} \% \mathrm{Cl}$. Annealing conditions are (1) $110^{\circ} \mathrm{C}$ for $20 \mathrm{~min}$; (2) $140^{\circ} \mathrm{C}$ for $15 \mathrm{~min}$; (3) $160^{\circ} \mathrm{C}$ for $15 \mathrm{~min}$; followed by (4) $110^{\circ} \mathrm{C}$ for $11 \mathrm{~h}$; (5) $160^{\circ} \mathrm{C}$ for $15 \mathrm{~min}$.

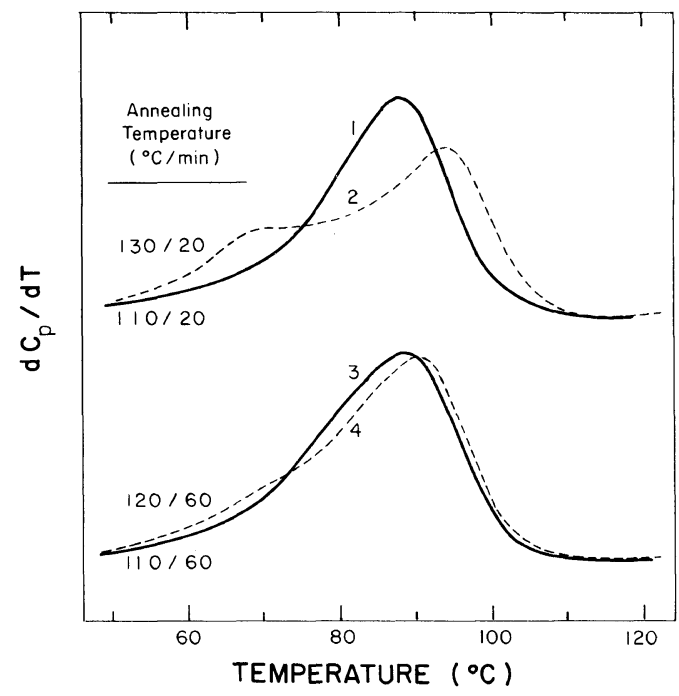

Figure 2. Derivative DSC thermograms $\left(\mathrm{d} C_{\mathrm{p}} / \mathrm{d} T\right.$ vs. $\left.T\right)$ of $50 / 50 \mathrm{wt} \%$ blends of isotactic poly(methyl methacrylate) and chlorinated polyethylene containing $62.0 \mathrm{wt} \% \mathrm{Cl}$. Annealing conditions are (1) $110^{\circ} \mathrm{C}$ for $20 \mathrm{~min}$; (2) $130^{\circ} \mathrm{C}$ for $20 \mathrm{~min}$; followed by (3) $110^{\circ} \mathrm{C}$ for $60 \mathrm{~min}$; (4) $120^{\circ} \mathrm{C}$ for $60 \mathrm{~min}$.

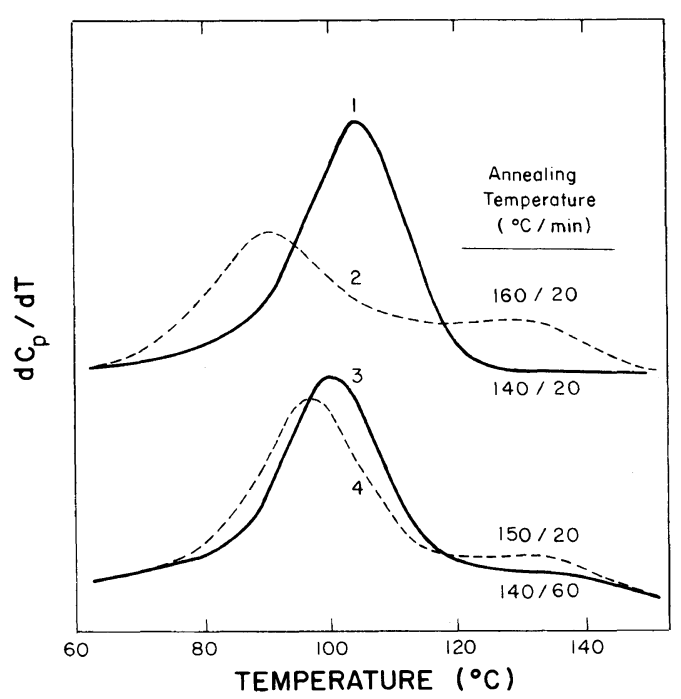

Figure 3. Derivative DSC thermograms $\left(\mathrm{d} C_{\mathrm{p}} / \mathrm{d} T v s . T\right)$ of $50 / 50 \mathrm{wt} \%$ blends of syndiotactic poly(methyl methacrylate) and chlorinated polyethylene containing $50.5 \mathrm{wt} \% \mathrm{Cl}$. Annealing conditions are (1) $140^{\circ} \mathrm{C}$ for $20 \mathrm{~min}$; (2) $160^{\circ} \mathrm{C}$ for $20 \mathrm{~min}$; followed by (3) $140^{\circ} \mathrm{C}$ for $60 \mathrm{~min}$; (4) $150^{\circ} \mathrm{C}$ for $20 \mathrm{~min}$. 


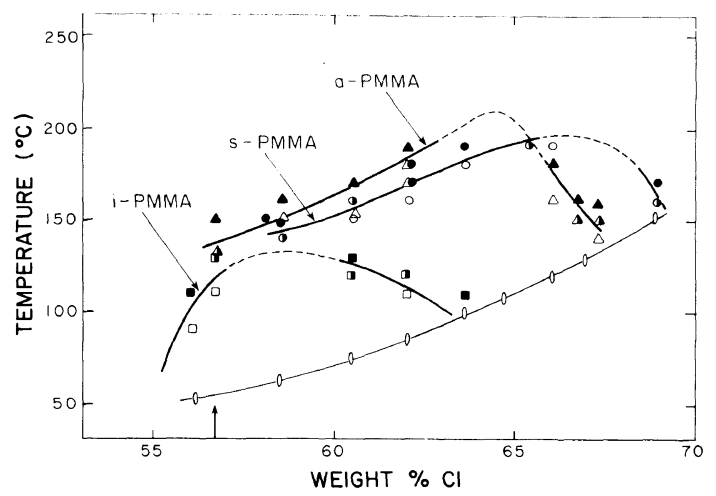

Figure 4. Miscibility of $50 / 50 \mathrm{wt} \%$ blends of i-PMMA $(\square, \square)$, s-PMMA $(\bigcirc, \bigcirc)$, and a-PMMA $(\triangle, \Delta)$ and CPE as a function of temperature and chlorine content. Open symbols, one phase; solid symbols, two phases. ( $\mathbf{\square}, \mathbf{\Delta})$ Partially miscible blends; $(-0-) T_{\mathrm{g}}$ 's of pure CPEs. Arrow indicates composition corresponding to equal mole fractions of $\mathrm{CH}_{2}$ and $\mathrm{CHCl}(c f$. $\mathrm{PVC}$ ).

below the respective LCST display a single peak that bifurcates when the sample is annealed above the critical temperature. The reversibility phase separation above LCST by rehomogenization below LCST was also confirmed, as shown in Figures 1-3.

Figure 4 shows miscibility diagrams, i.e., miscibility as a function of temperature and copolymer composition conveniently expressed in terms of chlorine content, for a-, i-, and s-PMMA/CPE blends. These three systems each display a miscibility window. The respective compositions (mole fraction of $\mathrm{CH}_{2}$ ) at the maximum temperature of miscibility are $x_{\mathrm{m}}^{\mathrm{i}}=0.464, \quad x_{\mathrm{m}}^{\mathrm{a}}=0.330$, and $x_{\mathrm{m}}^{\mathrm{s}}=0.302$. As expected from eq. $13, x_{\mathrm{m}}^{\mathrm{a}}$ is close to the average of $x_{\mathrm{m}}^{\mathrm{i}}$ and $x_{\mathrm{m}}^{\mathrm{s}}$, although $T_{\mathrm{m}}$ at $x_{\mathrm{m}}^{\mathrm{i}}\left(130^{\circ} \mathrm{C}\right)$ is lower than the $T_{\mathrm{m}}$ 's at $x_{\mathrm{m}}^{\mathrm{s}}$ and $x_{\mathrm{m}}^{\mathrm{a}}$ (about $200^{\circ} \mathrm{C}$ ). As a general comment, these data show that CPEs are apparently more miscible with a- and s-PMMA than i-PMMA over the entire range of chlorination. The $50 / 50 \mathrm{wt} \%$ blend compositions used do not necessarily correspond to the critical compositions formally used in the following analysis; in fact we have shown through the determination of complete phase diagrams for selected systems that the differ- ence in the temperature plane is less than $10^{\circ} \mathrm{C}$ and could therefore not account for the large differences between the tactic PMMA's observed in the composition plane in Figure 4. At the same time the considerable differences in molecular weights and molecular weight distributions between the tactic PMMA's must be considered. However, all the molecular weights are in a range in which their contribution to the configurational entropy is negligible, i.e., of the order of $n^{-1}$ in dimensionless $\chi$ units where $n$ is the degree of polymerization, (eq 6). Furthermore, an increase in the molecular weight of the atactic PMMA - the lowest of the three samples used-would have the effect of decreasing the size of the miscibility window shown in Figure 4 which would accentuate the effects described here. Molecular weight distribution differences, while important as a second order perturbation, will lead to more diffuse phase boundaries, but will again not significantly alter the location of the respective boundaries.

The miscibility boundaries for the systems are formally determined in a first order treatment by eq 7-9. A second order treatment, involving triad related interaction parameters, ${ }^{10-12}$ would of course improve the analysis but is in practice limited by the number of unknown parameters that need to be determined. Equations 7 and 8 each include three unknown interaction parameters, and eq 9 includes six unknown interaction parameters. One of these, $\chi_{\mathrm{AB}}\left(\mathrm{A} \equiv \mathrm{CH}_{2}, \mathrm{~B} \equiv \mathrm{CHCl}\right)$, has been determined experimentally from the miscibility boundary for CPE/CPE blends, ${ }^{14,27}$ and $\chi_{\mathrm{AC}}, \chi_{\mathrm{BC}}, \chi_{\mathrm{AC}^{\prime}}$, and $\chi_{\mathrm{BC}^{\prime}}$ can be estimated from eq 7 and 8 . The respective mole fractions of $\mathrm{CH}_{2}$ units of $\mathrm{CPE}$ at the miscibility boundary for s- and a-PMMA/CPE blends at $170^{\circ} \mathrm{C}$ are 0.380 and 0.186 for the system containing s-PMMA and 0.417 and 0.275 for the system containing a-PMMA. However, as reported previously, ${ }^{11} \chi_{\mathrm{AB}}$ depends on the degree of chlorination of the CPEs. Thus we use $\chi_{\mathrm{AB}}$ 's appropriate to each of the two 
boundary compositions for each system at $170^{\circ} \mathrm{C}$ : 0.14 and 0.3 for the s-PMMA-containing system and 0.09 and 0.31 for the a-PMMA-containing system. Because the iPMMA/CPE blend is immiscible at $170^{\circ} \mathrm{C}$, we use the boundary mole fractions for the i-PMMA/CPE systems at $110^{\circ} \mathrm{C}(0.508$ and 0.375); so the $\chi_{\mathrm{AB}}$ 's at the two compositions studied are 0.035 and 0.15 . Using these parameters and eq 7 and 8 with the assumption that all interaction parameters except $\chi_{\mathrm{AB}}$ are independent of the degree of chlorination of CPE, we can estimate the four binary interaction parameters: $\chi_{\mathrm{AC}}(110)=-0.08, \chi_{\mathrm{BC}}(110)=$ $0.117, \chi_{\mathrm{AC}^{\prime}}(170)=-0.004, \chi_{\mathrm{BC}^{\prime}}(170)=0.06$.

Turning now to the system containing atactic PMMA we find that because $\chi_{\mathrm{AC}^{\prime}}(170)$ and $\chi_{\mathrm{BC}^{\prime}}(170)$ were obtained above, only three unknown $\chi^{\prime} \mathrm{s}\left[\chi_{\mathrm{AC}}(170), \chi_{\mathrm{BC}}(170)\right.$, and $\left.\chi_{\mathrm{CC}}(170)\right]$ remain in eq 9 . We have estimated $\chi_{\mathrm{AC}}(110)$ and $\chi_{\mathrm{BC}}(110)$ at $110^{\circ} \mathrm{C}$ : both $\chi_{\mathrm{AC}}$ and $\chi_{\mathrm{BC}}$ are expected to increase as the temperature increases, because the system displays LCSTs. Thus we make the approximation $\chi_{\mathrm{AC}}(170)=$ $\chi_{\mathrm{AC}}(110) \alpha$ and that $\chi_{\mathrm{BC}}(170)=\chi_{\mathrm{BC}}(110) / \alpha$, where $\alpha(<1)$ is a constant; and using the above results, find

$$
\chi_{\mathrm{AC}}(170) \chi_{\mathrm{BC}}(170)=-0.0093
$$

Using eq 14 and the estimated values of $\chi_{\mathrm{AB}}$, $\chi_{\mathrm{AC}^{\prime}}$, and $\chi_{\mathrm{BC}^{\prime}}$, we calculated that $\chi_{\mathrm{AC}}(170)=$ $-0.02, \quad \chi_{\mathrm{BC}}(170)=0.477$, and $\chi_{\mathrm{CC}^{\prime}}(170)=$ -0.50 . A summary of the segmental interaction parameters finally obtained above are listed in Table I.

Surprisingly $\chi_{\mathrm{AC}}$ and $\chi_{\mathrm{AC}^{\prime}}$ have slightly negative values, a result formally indicating favorable interactions between $\mathrm{CH}_{2}$ units and methyl methacrylate units. Polyethylene is immiscible with PMMA, so these results appear to disagree with the experimental results; however, we are considering amorphous systems. This disparity may be the result of the assumption that the interaction parameters are independent of the degree of chlorination and also reflect the limitations of a first order
Table I. Interaction parameters of i-, s-, or a-PMMA/CPE blends

\begin{tabular}{ccc}
\multirow{2}{*}{ System } & \multicolumn{2}{c}{ Interaction parameter } \\
\cline { 2 - 3 } & Type $^{\mathrm{a}}$ & Value \\
\hline i-PMMA/CPE $\left(110^{\circ} \mathrm{C}\right)$ & $\chi_{\mathrm{AC}}$ & -0.08 \\
& $\chi_{\mathrm{BC}}$ & 0.117 \\
s-PMMA/CPE $\left(170^{\circ} \mathrm{C}\right)$ & $\chi_{\mathrm{AC}^{\prime}}$ & -0.004 \\
& $\chi_{\mathrm{BC}^{\prime}}$ & 0.06 \\
a-PMMA/CPE $\left(170^{\circ} \mathrm{C}\right)$ & $\chi_{\mathrm{AC}}$ & -0.02 \\
& $\chi_{\mathrm{AC}^{\prime}}$ & -0.004 \\
& $\chi_{\mathrm{BC}}$ & 0.477 \\
& $\chi_{\mathrm{BC}^{\prime}}$ & 0.06 \\
& $\chi_{\mathrm{CC}^{\prime}}$ & -0.50 \\
\hline
\end{tabular}

a $\mathrm{A} \equiv \mathrm{CH}_{2} ; \mathrm{B} \equiv \mathrm{CHCl} ; \mathrm{C} \equiv \mathrm{ADAD} ; \mathrm{C}^{\prime} \equiv \mathrm{ADAD}^{\prime} ; \mathrm{D} \equiv$ $\mathrm{CH}_{3} \stackrel{\text { C }}{\mathrm{C}}-\mathrm{COOCH}_{3} ; \mathrm{D}^{\prime} \equiv \mathrm{CH}_{3} \mathrm{OOC}-\mathrm{C}_{\mathrm{C}}^{\mathrm{C}}-\mathrm{CH}_{3}$.

treatment. We showed previously that comonomer sequence distribution affects the segmental interaction parameters of $\mathrm{CPE} / \mathrm{CPE}^{27}$ and $\mathrm{CPE} / \mathrm{CPVC}^{27}$ blends. Thus the interaction parameters for PMMA/CPE blends may also depend on the degree of chlorination as well as the $\mathrm{CHCl}$ sequence distribution along the polymer chain. However, as already noted, the available data is not sufficient in detail to extract the necessary quantitative information for interpretation in terms of triad interaction parameters.

If the $\mathrm{CHCl}$ sequence distribution in CPEs does influence miscibility in PMMA/CPE blends, then PMMA/CPVC mixtures will be expected to display miscibility behavior different from that of PMMA/CPE at identical chlorine contents because CPVCs and CPEs have substantially different microstructures in terms of $\mathrm{CH}_{2}$ and $\mathrm{CHCl}$ sequences.

Figure 5 shows miscibility plots for i-, s-, and a-PMMA/CPVC blends. These systems also show LCSTs, and it is clear that the miscibility behavior of PMMA/CPVC blends differs from that of PMMA/CPE blends: in general PMMA is more miscible with CPVCs than with CPEs; $x_{\mathrm{m}}^{\mathrm{i}}$ for the $\mathrm{i}-\mathrm{PMMA} / \mathrm{CPVC}$ blends is higher than $x_{\mathrm{m}}^{\mathrm{i}}$ for i-PMMA/CPE blends. The differences in the right-hand miscibility bound- 


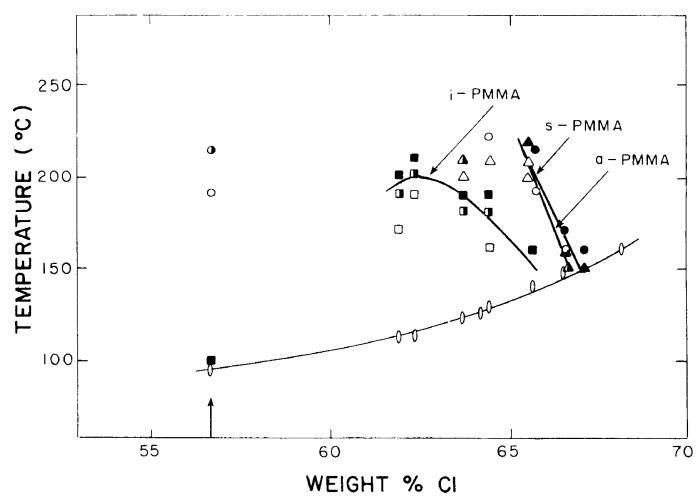

Figure 5. Miscibility of $50 / 50 \mathrm{wt} \%$ blends of i-PMMA $(\square, \square)$, s-PMMA $(\bigcirc, \boldsymbol{O})$, and a-PMMA $(\triangle, \boldsymbol{\Delta})$ and CPVC as a function of temperature and chlorine content. Open symbols, one phase; solid symbols, two phases. ( $, \square, \boldsymbol{\Delta})$ partially miscible blends; $(-0-) T_{\mathrm{g}}$ 's of pure CPVC's. Arrow indicates PVC composition.

aries for the atactic and syndiotactic PMMAs with, respectively, CPE and CPVC is less than for the isotactic case; this is to be expected because the microstructures of the two halogenated hydrocarbons converge at the highest chlorine contents. The differences between the miscibility behaviors of the PMMA/CPE blends and the PMMA/CPVC blends show definitively that the segmental interaction parameters for these systems depend on the microstructures of the CPEs and CPVCs. However, in the latter system, the lack of data covering the entire range of chlorine contents does not permit a quantitative evaluation of the parameters for the latter system. This result concerning sequence distribution was also found for the CPE/CPE and CPE/CPVC systems in even more accentuated form.

\section{CONCLUSIONS}

Blends of i-, s-, or a-PMMA and CPE or CPVC blends show LCSTs and display miscibility windows. Both CPE and CPVC are more miscible with s- and a-PMMA than with i-PMMA, and PMMA is in general more miscible with the CPVCs than with the CPEs.
The interaction parameters in these systems are functions of the $\mathrm{CHCl}$ sequence distribution in the CPEs and the CPVCs. The quantitative analysis presented inevitably contains a number of simplifying assumptions including inter alia the equivalance of $\mathrm{CCl}_{2}$ and $\mathrm{CHCl}$ units in CPE at low concentrations of the former, the equivalence of random and alternating copolymer microstructure in defining the sequence distributions of isotactic and syndiotactic PMMA, and in temperature corrections to certain $\chi$ 's. Even with these simplifications-necessitated by the limited data-set available - the first-order analysis offers new insights into the effect of tacticity and copolymer composition in this system.

Acknowledgment. This work was supported by a grant from B. F. Goodrich and by AFOSR 93-001.

\section{REFERENCES}

1. R. L. Scott, J. Polym. Sci., 9, 423 (1952).

2. S. Krause, A. L. Smith, and M. G. Dudon, J. Chem. Phys., 43, 2144 (1965).

3. R. Roe and W. Zin, Macromolecules, 13, 1221 (1980).

4. L. Leibler, Macromolecules, 13, 1602 (1980).

5. L. Leibler, Macromolecules, 15, 1283 (1982).

6. R. P. Kambour, J. T. Bendler, and R. C. Bopp, Macromolecules, 16, 753 (1983).

7. G. ten Brinke, F. E. Karasz, and W. J. MacKnight, Macromolecules, 16, 1827 (1983).

8. D. R. Paul and J. W. Barlow, Polymer, 25, 487 (1984).

9. M. D. Whitmore and J. Noolandi, Macromolecules, 18, 2486 (1985).

10. A. C. Balazs, I.C. Sanchez, I. R. Epstein, F. E. Karasz, and W. J. MacKnight, Macromolecules, 18, 2188 (1985).

11. A. C. Balazs, F. E. Karasz, W. J. MacKnight, H. Ueda, and I. C. Sanchez, Macromolecules, 18, 2784 (1985).

12. H. J. Cantow and O. Schulz, Polym. Bull., 15, 539 (1986).

13. M. A. Masse, H. Ueda, and F. E. Karasz, J. Macromolecules, 21, 3438 (1988).

14. H. Ueda and F. E. Karasz, J. Macromol. Sci. Chem., A27, 1693 (1990).

15. D. Lath, J. M. G. Cowie, and E. Lathova, Polym. Bull. (Berlin), 28(3), 361 (1992).

16. J. W. Schurer, A. de Boer, and G. Challa, Polymer, 


\section{H. UEDA and F. E. KARASZ}

16, 201 (1975).

17. J. Vanderschueren, A. Janssens, M. Ladang, and J. Niezette, Polymer, 23, 395 (1982).

18. E. J. Vorenkamp, G. ten Brinke, J. G. Meijer, H. Jager, and G. Challa, Polymer, 26, 1725 (1985).

19. Y. Zhao and R. E. Prud'homme, Macromolecules, 23, 713 (1990).

20. E. Roerdink and G. Challa, Polymer, 21, 1161 (1980).

21. D. J. Walsh, J. S. Higgins, and Z. Chai, Polymer, 23, 336 (1982).

22. Z. Chai, R. Sun, D. J. Walsh, and J. S. Higgins,
Polymer, 24, 263 (1983).

23. C. Tremblay and R. E. Prud'homme, J. Polym. Sci., Polym. Phys. Ed., 22, 1857 (1984).

24. E. Lemieux, R. E. Prud'homme, R. E. Forte, R. Jérome, and P. Teyssié, Macromolecules, 21, 2148 (1988).

25. T. Saito and K. Yamaguchi, Polymer, 15, 219 (1974)

26. J. A. Schroeder, F. E. Karasz, and W. J. MacKnight, Polymer, 26, 1795 (1985).

27. H. Ueda and F. E. Karasz, Polym. J., 24, 1363 (1992). 